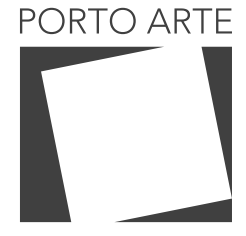

Revista de Artes Visuais

v. $25 n .43$ Jan/jun 2020 e-ISSN: 2179-8001

\title{
Tapeçaria enrolada: um caso no acervo do Margs
}

Rolled tapestry: a case in the Margs's collection

\section{Paulo César Ribeiro Gomes}

ORCID: 0000-0003-4661-6882

Universidade Federal do Rio Grande do Sul, Brasil

\section{Carolina Bouvie Grippa}

ORCID: 0000-0002-5848-0727

Universidade Federal do Rio Grande do Sul, Brasil

\section{Resumo}

Durante as décadas de 1970 e 1980, ocorreu um número significativo de exposições de tapeçarias no Museu de Arte do Rio Grande do Sul Ado Malagoli, resultando na aquisição de obras têxteis. Devido ao número considerável dessas peças, neste artigo discutiremos o espaço cedido a técnica no Margs, as dificuldades enfrentadas na sua legitimação e as razões que levaram a instituição a constituir um importante acervo de tapeçarias e dedicar uma sala especial para essas obras.

Palavras-chave Abstract

Tapeçaria. Exposições. Acervo. Museu de Arte do Rio Grande do Sul Ado Malagoli.

During the 1970s and 1980s, a significant number of tapestry exhibitions took place at the Rio Grande do Sul Ado Malagoli Art Museum, resulting in the acquisition of textile works. Due to the considerable number of these pieces, in this article we will discuss the space given to technique in Margs, the difficulties faced in its legitimation and the reasons that led the institution to constitute an important collection of tapestries and to dedicate a special room for these works.

Keywords

Tapestry. Exhibitions. Collection. Museum of Art of Rio Grande do Sul Ado Malagoli. 


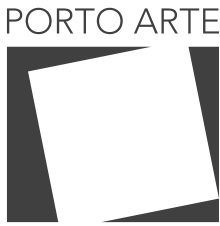

Revista de Artes Visuais

v. $25 n .43$ Jan/jun 2020 e-ISSN: 2179-8001
Quadro 1: Exposições e acervo Margs Fonte: Elaborado pela autora, a partir de dados da pesquisa (2019)
Dois anos após a abertura do Museu de Arte Moderna do Rio Grande do Sul ${ }^{1}$, ocorreu a primeira mostra envolvendo o suporte têxtil, expondo 14 tapeçarias $^{2}$ e 15 cartões do artista baiano Genaro de Carvalho ${ }^{3}$, considerado um dos pioneiros na tapeçaria moderna nacional (ARTISTAS..., 2012). 0 artista foi apresentado no catálogo da mostra como "um dos mais autênticos artistas brasileiros de seu tempo" (ALMEIDA, 1958, p. 2), fama que ganhou com suas tapeçarias, que na época já haviam sido expostas na primeira e na segunda Bienal de São Paulo (1951 e 1954). Devido ao reconhecimento do artista e da qualidade de sua obra, Ado Malagoli ${ }^{4}$ comprou uma das tapeçarias expostas (figura 1), sendo essa a primeira representante da arte têxtil na coleção do Margs ${ }^{5}$ (MARGS, [195-]). Na década seguinte, em 1960, não ocorreu exposição sobre o tema, mas as décadas de 1970 e de 1980 chamam a atenção pelo número de exposições e doações de têxteis ocorridos no museu, como se pode observar no quadro 1.

\begin{tabular}{|c|c|c|}
\hline DÉCADA & EXPOSIÇõES DE TAPEÇARIA & ACERVo \\
\hline 1950 & 1 exposição & 1 compra \\
\hline 1960 & 0 & 1 compra \\
\hline \multirow{2}{*}{1970} & 9 exposições & 196 doações \\
\hline 1980 & Abertura da Sala de tapeçaria & 8 doações \\
\hline 1990 & 17 exposições & 2 doações \\
\hline 2000 & 6 exposições & 1 doação \\
\hline 2010 & 1 exposição & 1 doação \\
\hline
\end{tabular}

\footnotetext{
1- O Museu de Arte do Rio Grande do Sul Ado Malagoli leva o nome do seu fundador, a partir de 1990. homem importante para a renovação da arte no Estado, que trabalhou para a constituição do Margs e no ensino da arte no Instituto de Belas Artes (atual Instituto de Artes da UFRGS). Criado em 1954, seguindo a abertura de outros museus estaduais, como o Museu de Arte de São Paulo Assis Chateaubriand (1947). o Museu de Arte Moderna de São Paulo (1948) e o Museu de Arte Moderna do Rio de Janeiro (1948), o Margs tinha o "objetivo de preservar e divulgar o patrimônio artístico e cultural do Estado e inseri-lo nas tendências da época" (SAFRA, 2001, p. 8). Assim, Ado Malagoli encarregou-se de selecionar e comprar as obras que pertenceriam ao museu, mostrando a importância na constituição desse acervo para consolidar a imagem do museu, que recém abri as suas portas (SAFRA, 2001). Mesmo que a primeira exposição do museu, em 1957, tenha sido sobre o pintor Pedro Weingärtner (1853 - 1929) e grande parte conhecida da coleção seja nesse suporte; ao longo dos anos, houve exposições que incluíam diversas técnicas artísticas, como gravura, pôsteres, escultura, cerâmica e tapeçaria, que é o tema deste artigo

2- Para identificar a diferenciação dos termos, cito Mônica Zielinsky (1985), que coloca a tapeçaria mais ligada ao bidimensional e a técnicas de tradições, como gobelin e a tapeçaria bordada. No século XX, modificações ocorreram na tapeçaria, influenciadas pelas produções de Lurçat, artistas poloneses e iugoslavos, ampliando-se o conceito a partir de um "reestudo das possibilidades técnicas desta produção e novas linguagens surgiram" (ZIELINSKY, 1985, p. 11). Portanto, arte têxtil identifica "ampliação da forma tradicional" da tapeçaria (ZIELINSKY, 1985, p. 12). No caso do acervo do Margs, temos exemplos de ambos, tanto de tapeçarias como de arte têxtil.

3- Salvador (BA), 1926 - 1971.

4- Araraquara (SP), 1906 - Porto Alegre (RS), 1994

5- No núcleo de documentação do MARGS, há o catálogo da exposição de Genaro de Carvalho, com a lista de obras expostas. A tapeçaria Horto da Espera, que foi adquirida pelo Margs, está na listagem. Na documentação da própria peça, há a primeira ficha catalográfica da tapeçaria Horta da Espera, na qual foi anotado o modo de aquisição: "adquirido do artista por ocasião de sua exposição oficial no Museu de Arte do Rio Grande do Sul em 1959" (MARGS, [195-]).

6- A autora acredita que as obras de Yeddo Titze, Renata Rubim e Joana de Azevedo Moura foram doadas na década de 1970, pois aparecem na listagem da Sala de Tapeçaria que foi aberta em 1979
} 


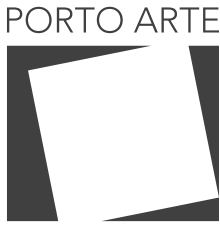

Revista de Artes Visuais

$\vee 25 n .43$

Jan/jun 2020 e-ISSN: 2179-8001

Há justificativas para as décadas de 1970 e 1980 se destacarem pela quantidade de exposições e doações, sendo um dos objetivos deste artigo expor algumas dessas razões, já que os dados se tornam significativos por esse ser um suporte não recorrente nas artes. No total, após a primeira tapeçaria adquirida, de Genaro de Carvalho, a coleção aumentou, chegando ao total de $34^{7}$ peças de arte têxtil, que atualmente são pouco expostas e divulgadas. A produção historiográfica parece ter passado ao largo de obras de artistas que trabalharam com o têxtil e esse desconhecimento reflete-se no atual esquecimento do precioso acervo têxtil do Margs. A maioria das peças está, literalmente, enrolada na reserva técnica, sem ser exposta há anos. Se em 2000 alguns desses trabalhos foram mostrados ao público, isso ocorreu em exposições com temas ligados a um saber feminino ou a uma "arte menor", conteúdos que, normalmente, são conectados a essa técnica e que, infelizmente, favorecem seu esquecimento na história da arte.

\section{A renovação da tapeçaria artística e o desenvolvimento da arte têxtil}

A quantidade de exposições sobre tapeçaria no Margs não é um dado isolado e reflete uma movimentação em prol da tapeçaria artística. Alguns artistas sulinos e de outras regiões do Brasil estavam produzindo nesse suporte dentro de um contexto de expressão e da grande visibilidade internacional dessa linguagem, motivados pelo conceito de Nova Tapeçaria, popularizado por Jean Lurçat ${ }^{8}$.

Houve uma expressiva valorização do suporte têxtil, na metade do século $X X$, tendo diversos artistas repensando esse meio, até então muito subordinado à pintura. Lurçat criou o Centro Internacional de Tapeçaria Antiga e Moderna (CITAM) em 1961, e a "Bienal Internacional de Tapeçaria de Lausanne" na Suíça, que durou 33 anos, sendo um marco para o fortalecimento da arte têxtil (CÁURIO, 1985). A primeira edição da "Bienal de Lausanne", em 1962, confirmou a característica mural da técnica, com muitas obras tecidas em grandes manufaturas nacionais francesas de Gobelins e Beauvais e os ateliês belgas de Chaudoir, Braquenié e Mechelen (COTTON; JUNET, 2017). Ao longo das edições, mudanças foram ocorrendo nas tradicionais tapeçarias, e os trabalhos dos tapeceiros poloneses começaram a ter destaque, pois esses teciam suas próprias peças no ateliê da União de Artistas Poloneses na Escola de Belas-Artes de Varsóvia (COTTON; JUNET, 2017). Esses artistas possuíam um interesse maior pelas propriedades dos materiais e pelos efeitos da trama, diferenciando seus trabalhos e realizando experimentações, cujo resultado levou a tapeçaria a "dar um salto ao espaço", conquistando a tridimensionalidade (COTTON; JUNET, 2017, p. 57).

$\mathrm{Na}$ quarta edição do evento, em 1969, diversos artistas abandonaram a parede, e suas criações eram suspensas no ar (COTTON; JUNET, 2017). Magdalena Abakanowicz ${ }^{9}$ apresentou sua obra Red Abakan, toda feita em sisal vermelho e presa ao teto, criando indagações sobre o rumo da tapeçaria no século XX: "Essa extraordinária, qua-

\footnotetext{
7- Das 34 peças de arte têxtil, quatro não possuem uma data precisa de doação, mas com informações e cruzamentos de dados, foi possível descobrir a década de doação de três obras. Apenas sobre a obra de Amarilli Boni Licht não foi possível descobrir a data de doação. 8- Bruyères (França), 1892 Saint-Paul-de-Vence (França), 1966 9- Falenty - Polônia, 1930 Varsóvia Polônia, 2017
} 


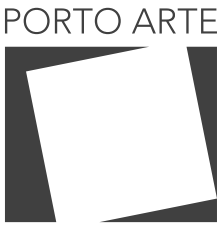

Revista de Artes Visuais

v. $25 \mathrm{n} .43$ Jan/jun 2020 e-ISSN: 2179-8001
Figura 1: DOUCHEZ, Jacques (Macon, França, 1921 - São Paulo, SP, 2012) Funambulesca, 1980. Lã, sisal e algodão em tear de baixo liço $134 \times 131 \mathrm{~cm}$ Aquisição por doação do artista 1982

Fotografia: Fabio del Re e Carlos Stein - Vivafoto Fonte: Acervo do Museu de Arte do Rio Grande do Sul - Margs. se orgânica peça, não parecia pertencer a nenhuma tradição. Isso é uma tapeçaria? Uma escultura? Um objeto têxtil?"10 (COTTON; JUNE, 2017, p. 57, tradução nossa). No mesmo ano, Jagoda Buic ${ }^{11}$ expôs Colombe blessée, uma composição escultural, construída com lã e sisal (COTTON; JUNET, 2017). Sua monumentalidade criava uma relação com o espaço expositivo, desenvolvendo uma nova dimensão para a arte têxtil: "O muro deixava de ser o único suporte: a tapeçaria ganhava definitivamente o espaço, podendo ser dependurada no teto com uma grande exploração de formas, vazados e texturas três valores que passaram a dar-Ihe nova feição" (CÁURIO, 1985, p. 104).

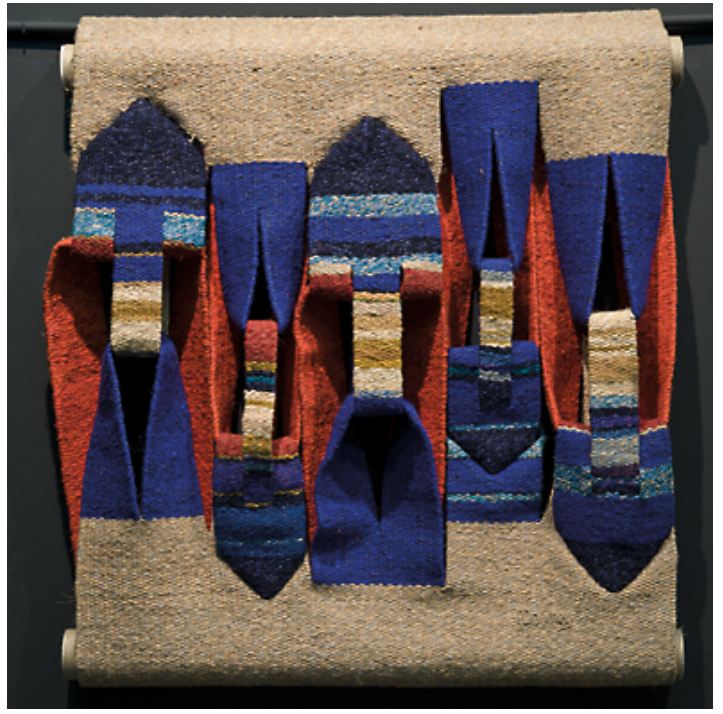

No Brasil, a renovação do suporte têxtil também motivou muitos artistas. O baiano Genaro de Carvalho, artista citado, criou o primeiro ateliê de tapeçaria de Salvador (Bahia), expondo em diversos países sua produção. No mesmo período, Jacques Douchez $^{12}$ e Norberto Nicola ${ }^{13}$ interessaram-se pela tapeçaria, recorrendo a Regina Gomide Graz $^{14}$ para orientá-los. Graz os ajudou e indicou a tecelã Gertrude Stuneff ${ }^{15}$ para ensinar-Ihes e deu um tear a eles (MATTAR, 2013). Em 1959, os dois abriram o ateliê de tapeçaria Douchez-Nicola, em São Paulo, onde criaram diversas obras próprias e convidaram artistas para elaborarem cartões, transpondo-os para o tear. Entre eles es-

\footnotetext{
10- Tradução para: "This extraordinary, almost organic piece did not seem to belong to any know tradition Was it a tapestry? A sculpture? A textile object?" (COTTON; JUNE, 2017, p. 57).

11- Split (Croácia), 1930

12- Macôn (França), 1921 - São Paulo (SP), 2012.

13- São Paulo (SP), 1930 - 2007

14- Itapetininga (São Paulo), 1897 - São Paulo (SP), 1973. Sua família transferiu-se, entre 1913 e 1920 para Genebra, onde ela estudou na Escola de Belas-Artes. Ao retornar a São Paulo, Regina Gomide Graz voltou-se às artes decorativas (termo utilizado na época), sendo muito reconhecida por seus trabalhos em têxteis com influências da Art Decó; chegou a participar da decoração da casa modernista do arquiteto russo Gregori Warchavchik em São Paulo (SIMIONI, 2007)

15- Não foi encontrada nenhuma informação sobre Stuneff.
} 


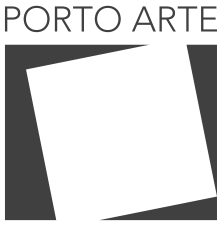

Revista de Artes Visuais

$\vee 25 n .43$

Jan/jun 2020 e-ISSN: 2179-8001

tavam Aldemir Martins ${ }^{16}$, Aldo Bonadei ${ }^{17}$, Alfredo Volpi ${ }^{18}$, Emiliano Di Cavalcanti ${ }^{19}$, Maria Leontina $^{20}$, Milton Dacosta ${ }^{21}$, Wega Nery ${ }^{22}$ e Yolanda Mohalyi ${ }^{23}$ (MATTAR, 2013, p. 54).

Influenciados pelas obras de Magdalena Abakanowicz e Jagoda Buic - ambas estiveram presentes em Bienais de São Paulo 24", Douchez e Nicola libertaram a tapeçaria do bidimensional, nomeando suas criações de "formas tecidas" (MATTAR, 2013). Desde 1968, os dois amigos já expunham experiências novas com o suporte têxtil, mas, de acordo com a curadora Denise Mattar, foi na exposição "Formas Tecidas" (Galeria Documenta, São Paulo), de 1969, que ocorreu o "salto para o espaço" (COTTON; JUNET, 2017, p. 57). Os dois artistas possuem obras no acervo do Margs, mas apenas a de Jacques Douchez (figura 4) é um exemplo da tapeçaria chamada de forma tecida, com uma projeção para o espaço e uma busca por tridimensionalidade. Foi nesse mesmo período que dois artistas sulinos, Zoravia Bettiol ${ }^{25}$ e Yeddo Titze ${ }^{26}(1935-2016)$, foram à Europa em busca de uma formação consistente em tapeçaria.

Zoravia Bettiol, artista de múltiplos suportes, ganhou muita visibilidade com sua gravura e possui uma grande relevância no desenvolvimento da arte têxtil. Formada em 1952, em artes plásticas, no Instituto de Belas Artes $^{27}$, seu interesse pelo têxtil surgiu na metade da década de 1950, já expondo uma tapeçaria no " $21^{\circ}$ Salão Pan-Americano de Arte"28 (1958). Mas foi apenas em 1968 que Zoravia viajou à Polônia para aprimorar seu conhecimento no tear. Morando por sete meses na cidade de Varsóvia, a artista estudou arte têxtil no ateliê de Maria Łaszkiewicz ${ }^{29}$ (RAMOS; GOMES, 2017).

A escolha de Zoravia pela Polônia não foi deliberada, pois era nesse país europeu que os "artistas têxteis poloneses se apresentavam na linha de frente da renovação em termos de técnica e de linguagem" (CARVALHO, 2007, p. 88). Como consequência da sua experiência na Polônia, seu trabalho se modificou e ganhou uma linguagem mais contemporânea, permanecendo, entretanto, com seu costume de trabalhar por séries.

As séries se sucederiam desde então, alternando materiais (algodão, sisal, pedras, conchas, estruturas metálicas), técnicas (tecelagem, tramado, bordado) e formas (cheios e vazados, camadas e sobreposições, estruturas bidimensionais e tridimensionais). A artista também adotaria ora um viés mais popular, verificado nos estandartes, ora um caminho mais imponente e com vigorosa estrutura formal, como na série Metamorphoses (1977), abrindo ao espectador, inclusive, certa flexibilidade quanto à inter-relação entre as partes (RAMOS; GOMES, 2017, p. 62).

\footnotetext{
16- Aurora (CE), 1922 - São Paulo (SP), 2006.

17- São Paulo (SP), 1906 - 1974

18- Lucca (Itália), 1896 - São Paulo (SP), 1988

19- Rio de Janeiro (RJ), 1897 - 1976.

20- São Paulo (SP), 1917 - Rio de Janeiro (RJ), 1984

21- Niterói (RJ), 1915 - Rio de Janeiro (RJ), 1988

22- Corumbá (MS), 1912 - Guarujá (SP), 2007.

23- Cluj - Napoca (Romênia), 1909 - São Paulo (SP), 1978

24- Magdalena Abakanowick participou da $7^{\text {a }}$ Bienal de São Paulo (1973), da $8^{a}$ Bienal (1965) e da $15^{a}$

Bienal (1979); e Jagoda Buic participou da 13ª Bienal (1975) e da 15ª Bienal (1979).

25- Porto Alegre (RS), 1935

26- Santana do Livramento (RS), 1935 - Porto Alegre (RS), 2016.

27- Atual Instituto de Artes da Universidade Federal do Rio Grande do Sul (UFRGS)

28- Mostra de comemoração do cinquentenário de fundação do Instituto de Belas Artes (IBA, 1958).

29- Griva (Polônia), 1891 - Varsóvia (Polônia), 1981.
} 


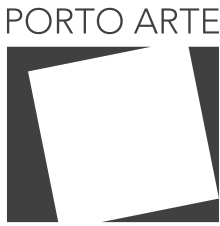

Revista de Artes Visuais

v. 25 n. 43 Jan/jun 2020 e-ISSN: 2179-8001
Figura 2: BETTIOL, Zoravia (Porto Alegre, RS, 1935) Série Metamorfose: Rapsódia, 1977

Tapeçaria manual com sisal

madeira e estrutura de ferro, $237 \times 60 \times 30 \mathrm{~cm}$. Aquisição por doação da artista, 1979 Fotografia: Fabio del Re e Carlos Stein - Vivafoto Fonte: Acervo do Museu de Arte do Rio Grande do Sul - Margs.

Figura 3: BETTIOL, Zoravia (Porto Alegre, RS, 1935)

Transfigurações da pedra I: tapeçaria $n^{\circ} 58,1983$ Tecelagem manual com algodão e pedra $71 \times 134 \mathrm{~cm}$. Aquisição por doação da artista, 1984 Fotografia: Fabio del Re e Carlos Stein - Vivafoto Fonte: Acervo do Museu de Arte do Rio Grande do Sul-Margs
Zoravia tem duas obras, de séries diferentes, no acervo do Margs. A primeira, doada em 1979, é Rapsódia (Série Metamorfose) (figura 4). É uma peça inusitada no seu modo de construção, pois o suporte em ferro, que faz parte do trabalho final, substituiu o tear. Também o trabalho tem a característica de não se ater a uma maneira definitiva de exibição, podendo haver uma interação maior entre o visitante e o espaço expositivo.
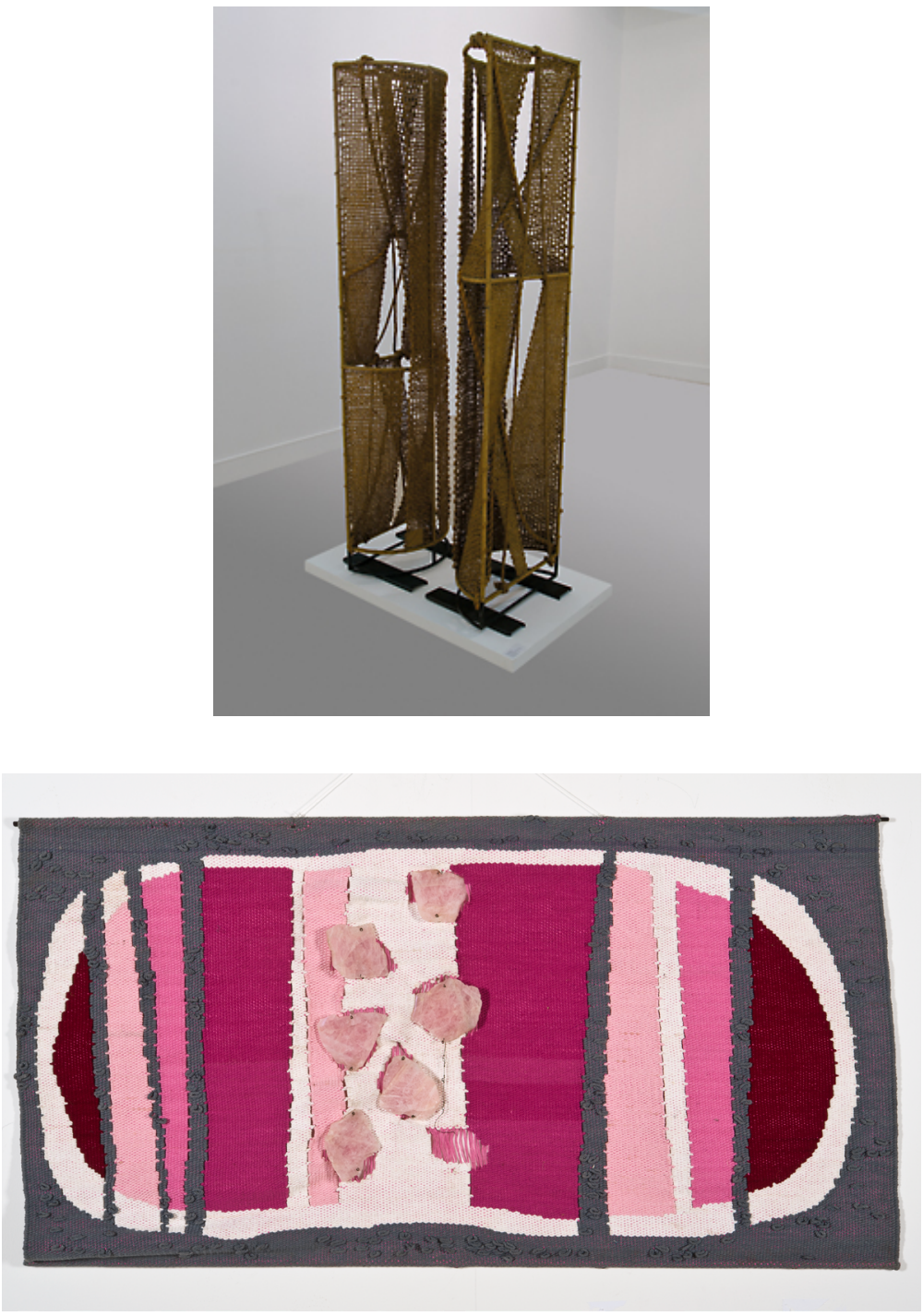

Posteriormente, Zoravia doou uma tapeçaria bidimensional, representante da série Transfigurações de pedra (figura 5). Nessa série, a artista, durante a tecelagem, incluiu objetos naturais, como pedras e conchas, inspiradas nas próprias formas da natureza na sua construção. Ambas as obras, são de execução posterior à viagem de 


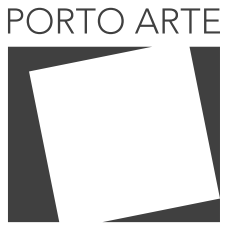

Revista de Artes Visuais

v. 25 n. 43

Jan/jun 2020 e-ISSN: 2179-8001
Figura 4: TITZE, Yeddo (Santana do Livramento/RS, 1935 - 2016) Alvorada, 1976. Tear manual de baixo liço com fios de lã e tecidos rasgados $200 \times 100 \mathrm{~cm}$ Aquisição por doação do artista. s.d. Fotografia: Fabio del Re e Carlos Stein - Vivafoto Fonte: Acervo do Museu de Arte do Rio Grande do Sul MARGS (Porto Alegre, RS) $<$ ? >- No texto de Yeddo Titze

(2005, p. 177), redigido em comemoração aos 50 anos do Margs, ele escreveu: "Após anos, encontro uma tapeçaria de minha autoria no acervo. Este trabalho havia estado, em 1976, em um leilão no Palácio Piratini, e posteriormente foi doada ao Museu. Na época, eu residia em

Brasília, e só soube da referida doação anos depois, quando retornei a nossa Capital". Com essa citação, acredita-se que fol - Palácio Piratini que doou a obra ao Margs, e não o próprio artista, como está escrito e divulgado nos créditos da obra.
Zoravia a Varsóvia.

Após seu período de estudos na Polônia, Zoravia iniciou a difusão da tapeçaria no Rio Grande do Sul, dando aulas para uma nova geração de artistas têxteis, como Carla Obino $^{30}$, Erica Turk ${ }^{31}$, Heloísa Crocco ${ }^{32}$, Liciê Hunsche ${ }^{33}$, Maria Helena Cavalcante ${ }^{34}$, Rachela Gleiser ${ }^{35}$, Ronete Magrisso ${ }^{36}$ e Sonia Moeller ${ }^{37}$. Muitas dessas integrariam ${ }^{38}$, na década de 1980, o Centro Gaúcho da Tapeçaria Contemporânea (CGTC), incentivando e

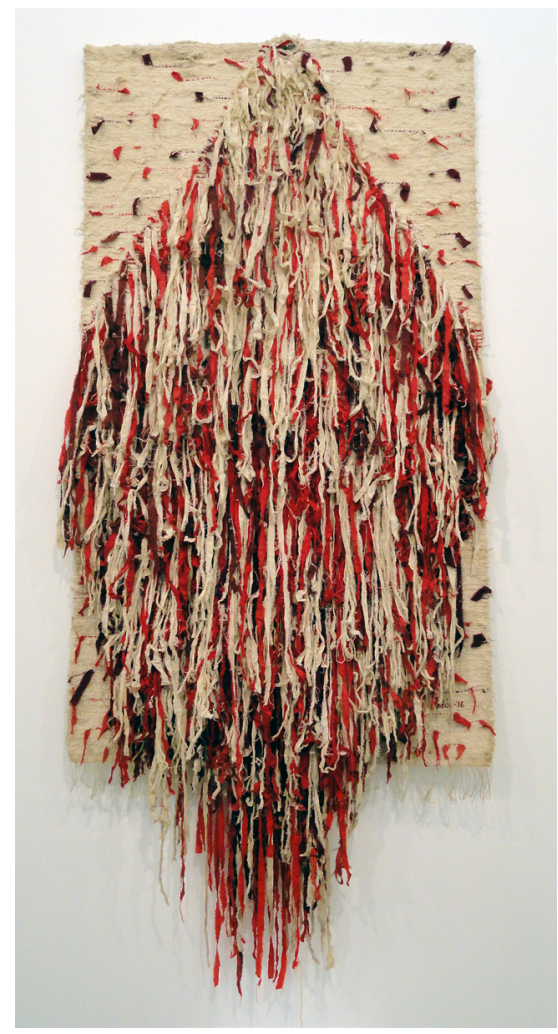

divulgando a tapeçaria.

Outro incentivador do têxtil no Rio Grande do Sul foi Yeddo Titze, professor na Universidade Federal de Santa Maria, de 1964 até fim dos anos 1970, onde deu aulas sobre a técnica (FOLETTO; BISOGNIN; FOLETTO, 2001). Entre 1960 e 1962, usufruiu de

\footnotetext{
30- Porto Alegre (RS), 1913 - 2005.

31- Rio Grande (RS), 1915 - Porto Alegre (RS), 2011

32- Porto Alegre (RS), 1949

33- Porto Alegre (RS), $1924-2017$

34- Pelotas (RS), 1939.

35- Porto Alegre (RS), 1932

36- Porto Alegre (RS), 1948

37- Porto Alegre (RS), 1942

38- Além de integrar o CGTC, todos os nomes citados, exceto Sonia Moeller, doaram obras para o acervo do Margs.
} 


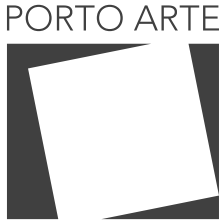

Revista de Artes Visuais

v. 25 n. 43 Jan/jun 2020 e-ISSN: 2179-8001
Figura 5: DOTTO, Ivandira

(Restinga Seca/RS, 1941) Pássaro da Primavera, 1974 Tapeçaria, batik e bordado com lã, $124 \times 95.5 \mathrm{~cm}$. Aquisição por doação da artista, 1976 Fotografia: Fabio del Re e Carlos Stein - Vivafoto Fonte: Acervo do Museu de Arte do Rio Grande do Sul - Margs. uma bolsa de estudos, concedida pelo governo francês, estudando em Paris com André Lhote $^{39}$ e, na École Nationale Superieure des Arts Decóratifs, com Marcel Gromaire ${ }^{40}$. Retornou à França em 1968, para estudar tapeçaria em Aubusson e, quando voltou a Santa Maria, dedicou-se ao ensino da arte têxtil, que era pouco difundida na região (FOLETTO; BISOGNIN, 2001). Titze deu um curso inicial, no qual ensinou a técnica da

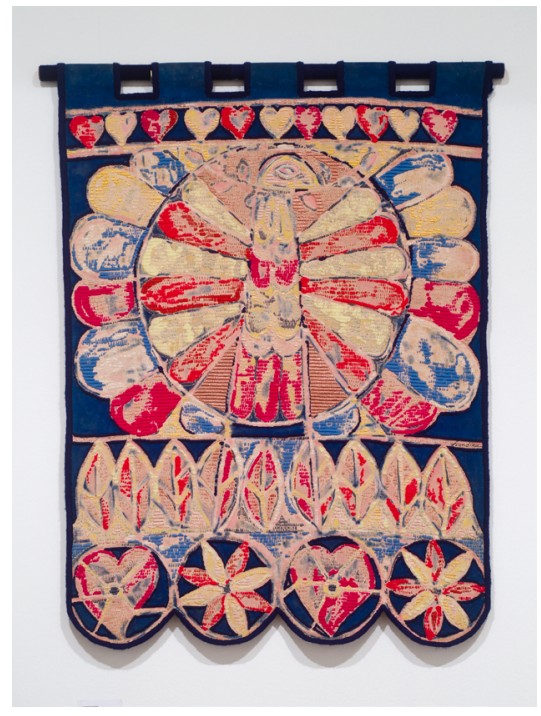

Figura 6: CROCCO, Heloísa Crocco (Porto Alegre/RS, 1949) Eco II, 1978. Tecelagem manual, madeira e fibras, $251.5 \times 97$ $26 \mathrm{~cm}$ Aquisição por doação da artista, 1979 Fotografia: Fabio del Re e Carlos Stein - Vivafoto Fonte: Acervo do Museu de Arte do Rio Grande do Sul - Margs.

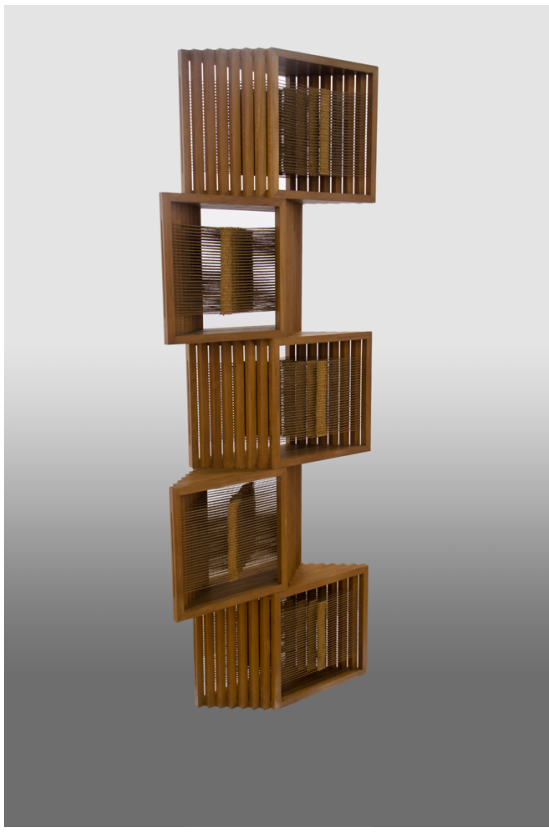




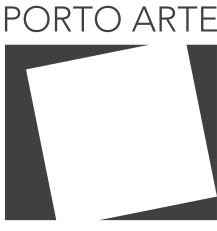

Revista de Artes Visuais

v. 25 ก. 43 Jan/jun 2020 e-ISSN: 2179-8001

tapeçaria de recorte para professores do curso de artes da UFSM, como Ana Norogrando ${ }^{41}$, Ivandira Dotto ${ }^{42}$, Berenice Gorini ${ }^{43}$, Luiz Gonzaga ${ }^{44}$ e Lia Achutti ${ }^{45}$ (GONZAGA, 2018, informação verbal). Exceto Luiz Gonzaga, que somente realizou uma exposição das tapeçarias ${ }^{46}$,Norogrando, Gorini e Dotto, seguiram com uma produção têxtil e todas possuem trabalhos representativos dessa época no acervo do MARGS, assim como o próprio Yeddo Titze. 0 trabalho do artista (Figura 6), inscrito no acervo do MARGS, demonstra, em três sentidos, uma quebra com a tapeçaria tradicional: a abstração, o uso diferenciado de materiais e uma busca pela liberação do suporte bidimensional.

Com a popularização do suporte, tanto no Rio Grande do Sul como em outras regiões do Brasil, ocorreram diversas exposições importantes sobre o tema, na década 1970, marcando um período de grande agitação e renovação para o têxtil, como aponta Gradim (2016, p. 131):

Por essa ocasião, uma intensa movimentação já se havia formado em torno da artêxtil: em todo o mundo criavam galerias e eventos especializados, inspirados diretamente nas Bienais de Lausanne - como a Trienal de Lodz polonesa (1975) - ou nascida com contraposição a elas - como a promissora Bienal dos Minitêxteis londrina (1974), a primeira a questionar a vinculação automática de "expressão monumental" às criações tecidas. Cada país criava seu evento nacional, como o próprio Brasil com a "I Mostra de Tapeçaria Brasileira" da Fundação Armando Álvares Penteado (1974, SP).

A "I Mostra de Tapeçaria Brasileira no MAB" " Museu de Arte Brasileira, da FAAP - Fundação Armando Álvares Penteado (1974) foi um evento expressivo que possibilitou "uma visão geral do que os tapeceiros brasileiros estão realizando" (FUNDAÇÃO..., 1974 , p. 2). A mostra teve exibiu 155 tapeçarias de 75 artistas, dentre os quais listamos Arlinda Volpato ${ }^{47}$, Burle Marx ${ }^{48}$, Berenice Gorini, Carla Obino, Fanny Meimes ${ }^{49}$, Genaro de Carvalho, Ivandira Dotto, Jacques Douchez, Jean Gillon ${ }^{50}$, Joana de Azevedo Moura $^{51}$, Liciê Hunsche, Madeleine Colaço ${ }^{52}$, Norberto Nicola, Renata Rubim ${ }^{53}$, Regina Gomide Graz, Sonia Moeller, Zoravia Bettiol e Yeddo Titze (FUNDAÇÃO..., 1974). No acervo do Margs, encontra-se a obra de Ivandira Dotto exposta nessa mostra, intitulada Pássaro da Primavera (figura 7).

No mesmo ano, ocorreu a "Mostra de Tapeçaria Brasileira", na Universidade Federal de Minas Gerais, com obras de Bia Vasconcellos ${ }^{54}$, Genaro de Carvalho, Jacques

\footnotetext{
41- Cachoeira do Sul (RS), 1951 42- Restinga Seca (RS), 1941.

43- Nova Veneza (SC), 1941

44- Julio de Castilhos (RS), 1940

45- Santa Maria (RS), 1928

46- Na entrevista concedida à autora, Gonzaga comenta que trabalhou com tapeçarias apenas durante um ano e meio, o que resultou em exposição na Galeria Eucatex, em 1973. Depois, não realizou mais tapeçarias (GONZAGA, 2018, informação verbal).

47- Tubarão (SC), 1946

48- São Paulo (SP), 1909 - Rio de Janeiro (RJ), 1994

49- Porto Alegre (RS), 1922 - 2011

50- Iasi (Romênia), 1919 - São Paulo (SP), 2007

51- Sobradinho (RS), 1951

52- Tanger (Marrocos), 1907 - Rio de Janeiro (RJ), 2001

53- Rio de Janeiro (RJ), 1948

54- Rio de Janeiro (RJ), 1946
} 


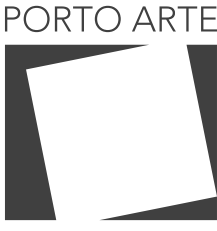

Revista de Artes Visuais

v. 25 n. 43 Jan/jun 2020 e-ISSN: 2179-8001
Quadro 2: Exposições e acervo Margs da década de 1970 Fonte: Elaborado pela autora com dados da pesquisa (2019)
Douchez, Marlene Trindade ${ }^{55}$, Norberto Nicola, Rubem Bario ${ }^{56}$, Zoravia Bettiol e mais dez $\operatorname{artistas}^{57}$ (UNIVERSIDADE, 1974). Posteriormente, ocorreu no Museu de Arte Moderna de São Paulo, a "Trienal de Tapeçaria", que teve edições em 1976, 1979 e 1982. Esse foi um dos maiores eventos nacionais na área, contando com 119 artistas participantes nas três edições (GRADIM, 2016). Do Rio Grande do Sul, na primeira edição, tivemos a participação de 14 artistas, na segunda de 13 artistas e na terceira edição de oito, estando presentes, entre outros, Arlinda Volpato, Berenice Gorini, Carla Obino, Fanny Meimes, Ivandira Dotto, Liciê Hunsche, Renata Rubim, Salomé Steinmetz ${ }^{58}$, Sonia Moeller, Yeddo Titze e Zoravia Bettiol (GRADIM, 2016). Destacamos a participação da artista Heloísa Crocco, que teve a obra Eco II (figura 8), exposta na $2^{\text {a }}$ edição da Trienal, peça que hoje se encontra no acervo do Margs.

Com toda a movimentação nacional em prol da tapeçaria, não é coincidência que as décadas de 1970 e 1980 sejam aquelas com um maior número de exposições e de doações de obras de arte têxtil para o Margs. Isso reflete uma abertura no museu à técnica e interesse em conservá-lo.

\begin{tabular}{|c|c|c|c|}
\hline ANO & EXPOSIÇÃO DE TAPEÇARIA & TÍTULO DA EXPOSIÇÃO & DOAÇÕES PARA O ACERVO DO MARGS \\
\hline 1972 & 1 & $\begin{array}{c}\text { Tapetes e artefatos, tecidos pelas alunas } \\
\text { de Zoravia Bettiol }\end{array}$ & \\
\hline \multirow{2}{*}{1973} & \multirow{2}{*}{2} & Tapeçarias de Minor Tomita & \\
\hline & & Tapeçarias de Wilhelm Hovart & \\
\hline 1974 & 0 & & $\begin{array}{c}\text { Doação de Minor Tomita e Wilhelm } \\
\text { Hovart }\end{array}$ \\
\hline 1975 & 2 & $1^{\mathrm{a}}$ Mostra Gaúcha de tapeçaria & \\
\hline \multirow[b]{2}{*}{1976} & \multirow[b]{2}{*}{2} & Tapetes de Carla Obino & Ivandira Dotto \\
\hline & & Acervo Margs: tapeçarias & $\begin{array}{c}\text { Carla Obino } \\
\text { Arlinda Volpato } \\
\text { Compra de Berenice Gorini }\end{array}$ \\
\hline \multirow[t]{2}{*}{1977} & \multirow[t]{2}{*}{2} & $\begin{array}{l}\text { Exposição dos alunos da Universidade de } \\
\text { Santa Maria, pintura, desenho, gravura, } \\
\text { tapeçaria e [objeto] }\end{array}$ & \\
\hline & & Acervo Margs: tapeçaria & \\
\hline 1978 & 1 & $\begin{array}{c}\text { Tapeçaria de Carla Obino realizada em } \\
\text { Caxias do Sul }\end{array}$ & $\begin{array}{l}\text { Joana de Avezedo, Swami Prem. } \\
\text { (Claudio do Couto e Silva) }\end{array}$ \\
\hline
\end{tabular}

55- Santa Bárbara (MG), 1932 - Belo Horizonte (MG), 2018

56- Rio de Janeiro (RJ), 1941 - 1978

57- Participaram também da exposição: Iracy Nietsche, Ignez Turazza, Alice Carracedo Djarte, Maria Kikoler, Inge Roesler, P. Parodi, Gilda Azevedo, Minnie Sardinha, Augusto Degois, Maria Helena Andres Ribeiro (UFMG, 1974).

58- Osório (RS), 1932 - Porto Alegre (RS), 2002 

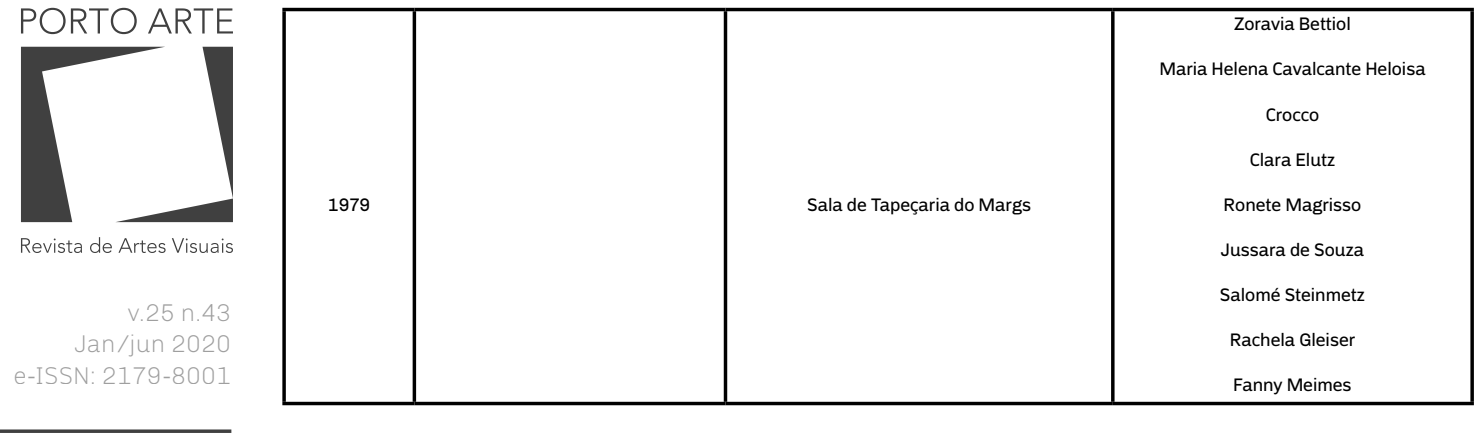

\section{Década de 1970: o fortalecimento do têxtil}

Na década de 1970, ocorreram nove exposições sobre o tema no Margs, sendo quatro delas mostras individuais (Minor Tomita ${ }^{59}$, Whilhelm Horvath ${ }^{60}$ e duas mostras de Carla Obino) e cinco mostras coletivas (alunas de Zoravia Bettiol, "1 $1^{a}$ Mostra Gaúcha de Tapeçaria", exposição de alunos de Santa Maria e duas exposições do acervo do Margs). No quadro 1, constam as informações sobre as exposições e as doações

No quadro 2, fica claro que se tornou recorrente a doação de obras de artistas que realizaram exposições no local. Porém, o ano de 1979 chama a atenção, pois foi quando ocorreu o maior número de doações de tapeçaria, que resultaram na abertura da Sala de Tapeçaria. Devido ao seu ineditismo e ao pouco conhecimento sobre o tema, é importante se ater à sala.

\subsection{A Sala de Tapeçaria do Margs}

Ao longo de 2017, a autora pesquisou o acervo documental do Centro Gaúcho da Tapeçaria Contemporânea (CGTC), como parte do trabalho de conclusão de curso ${ }^{61}$. 0 arquivo, composto de diversas cartas, boletins e atas, foi a base de pesquisa para o texto, esclarecendo questões sobre a trajetória do grupo, que será mais bem explicado a frente. Lendo as cartas, encontrei a seguinte mensagem, datada de 2 de maio de 1984 e endereçada à diretora do Margs, a socióloga Evelyn Berg Ioschpe ${ }^{62}$ :

\section{Senhora Diretora}

Dirigimo-nos a Vossa Senhoria para consultar do interesse deste Museu em colocar, na sala de tapeçaria, catálogos das duas Mostras de Tapeçaria promovidas pelo Centro Gaúcho da Tapeçaria Contemporânea, para serem distribuídos para pessoas interessadas nesta categoria de arte (MAGRISSO, 1984, grifo nosso). 


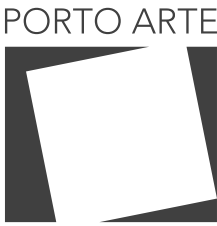

Revista de Artes Visuais

v. 25 ก. 43 Jan/jun 2020 e-ISSN: 2179-8001
Figura 7: Sala de Tapeçaria, com obras de Zoravia Bettiol, Rachela Gleiser, Carla Obino e Ronete Magrisso. Fonte: Núcleo de Documentação Margs (197-)
Questionando as associadas do CGTC sobre a Sala de Tapeçaria, nas entrevistas que realizei em 2017, ninguém se recordava da sala especifica, apenas que o Margs sempre cedeu espaço para exposições do Centro (tratarei do assunto adiante). Porém, o que a memória não recorda, a documentação mostra, e foi o que correu nas documentações no acervo do próprio Margs.

Durante o período de 23 de outubro a 26 de outubro de 1979, houve palestras e aberturas de exposição no evento que se intitulou "Semana do Museu". Palestras de Armindo Trevisan, com o tema "Panorama da Escultura Gaúcha Contemporânea", e Norberto Nicola, sobre "Origens da Arte de Tecer na América do Sul", fizeram parte da programação, além da abertura da "Nova Sala de Tapeçaria" (BOLETIM, 1979).

A sala abriu para exposição em 23 de outubro de 1979, no primeiro andar do museu, com a exposição de 16 artistas ${ }^{63}$. Dessas artistas, oito ${ }^{64}$ doaram obras, no mesmo ano da abertura da sala, sendo possível considerar que houve uma pesquisa anterior à abertura da sala para algumas artistas doarem suas obras ou emprestarem, com a proposta de serem expostas na sala. Uma carta de resposta, da artista Sonia Moeller ao diretor do museu, corrobora essa afirmação. No documento, escrito em 8 de setembro de 1979, lê-se:

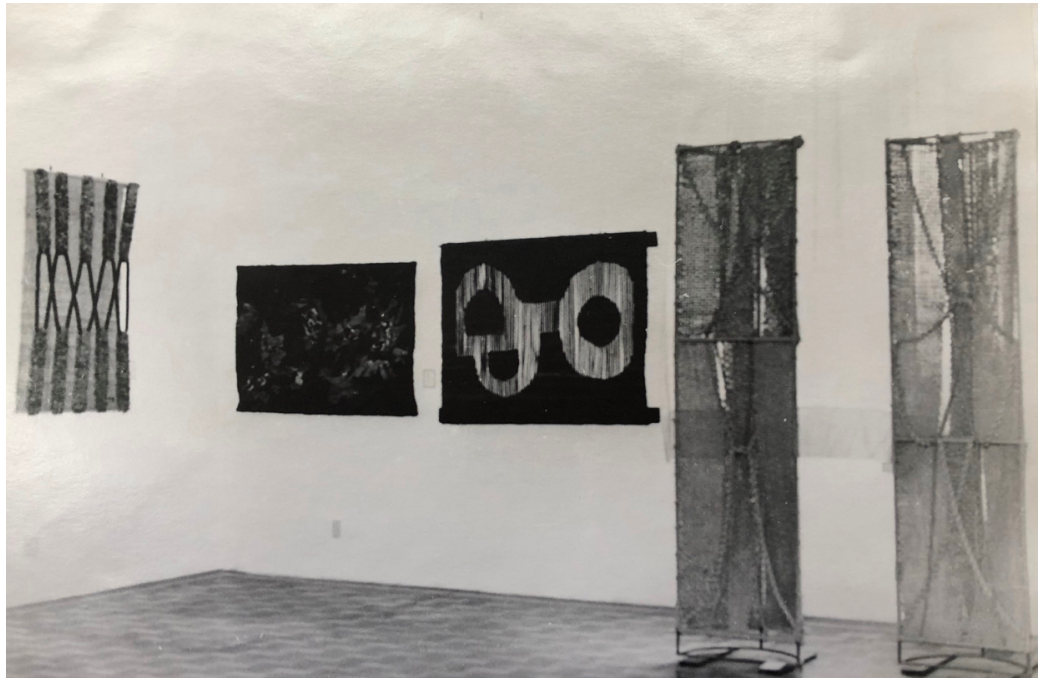

Atendendo a um convite de V.S. no sentido de fazer representa uma obra minha na Sala Permanente de Tapeçaria deste museu, faço entrega nesta data da seguinte tapeçaria: Título - Expansão II; Dimensões - 116 x 168 cm; Ano - 1979. A obra referida ficará aos cuidados do Museu a título de empréstimo, por um período de quatro meses contados a partir da data de entrega da mesma a esta Entidade. No entanto a autora se reserva o direito de retirar a obra dentro deste período, se dela necessitar para outros fins (MOELLER, 1979).

\footnotetext{
63- Arlinda Volpato, Berenice Gorini, Carla Obino, Fanny Meimes, Heloisa Crocco, Ivandira Dotto, Joana de Azevedo Moura, Jussara Cirne de Souza, Liciê Hunsche, Maria Helena Cavalcante, Rachela Gleiser, Ronete Magrisso, Salomé Steinmetz, Sonia Moeller, Yeddo Titze e Zorávia Bettiol (MARGS, 1979). 64-Zoravia Bettiol, Maria Helena Cavalcante, Heloisa Crocco, Ronete Magrisso, Jussara de Souza, Salomé Steinmetz, Rachela Gleiser e Fanny Meimes.
} 


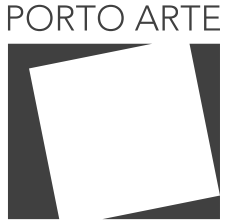

Revista de Artes Visuais

v. $25 n .43$ Jan/jun 2020 e-ISSN: 2179-8001

Figura 8: Sala de Tapeçaria com obras de Berenice Gorini Salomé Steinmetz e Joana de Azevedo Moura Fonte: Núcleo de Documentação Margs (197-)

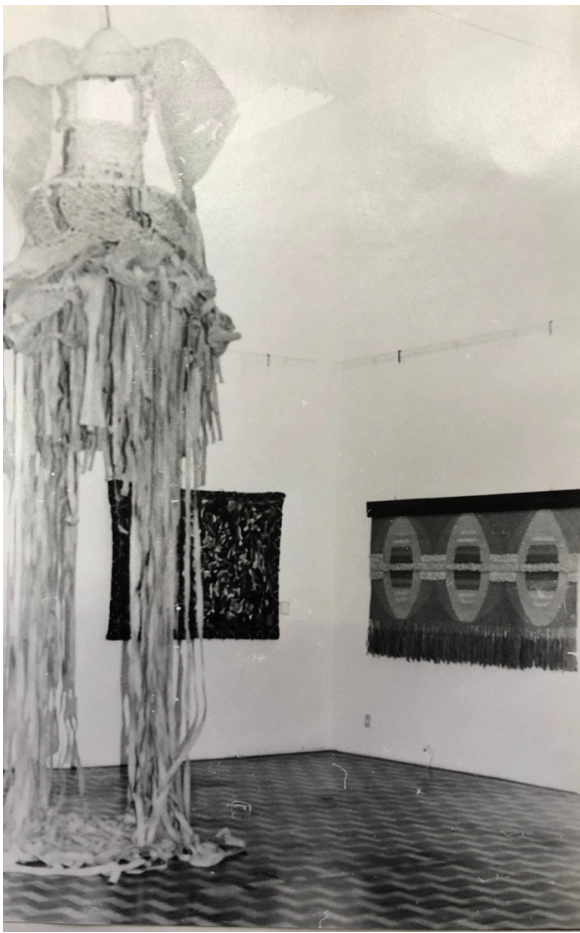

Assim, torna-se claro que houve um planejamento da instituição em conseguir mais obras para expor na nova sala. E, em alguns casos, houve doações ao museu, aumentando o número de obras têxteis em seu acervo.

Há duas imagens da sala, nas quais podemos ver sete obras expostas, em sua maioria do acervo do museu, sendo fácil o reconhecimento dessas. Na figura 8, da direita para esquerda, veem-se Rapsódia da Série Metamorfose (1977), de Zoravia Bettiol, Fases da lua (1979), de Rachela Gleiser, Girassóis (1976) e X Negro (1978), de Ronete Magrisso, todas do acervo do Margs.

Na segunda imagem disponível da exposição, temos visível a obra Orunko: Axó Iemenjá (s. d.,) de Berenice Gorini, em destaque, no lado esquerdo da imagem. Atrás, temos duas tapeçarias de parede, Brasiliensis: 0 imperador acredita na generosidade dos estranhos (1976), de Salomé Steinmetz, e uma obra de Joana de Azevedo Moura ${ }^{65}$.

A partir das poucas informações disponíveis sobre a sala, acredito que, em sua maioria, eram expostas obras do próprio acervo do museu ${ }^{66}$, para justamente valorizar a coleção do Margs e tornar mais conhecida a arte têxtil, que ganhava novas iniciativas e o engajamento de diversos artistas. A partir de reportagens nos jornais e da divulgação da sala, é possível confirmar que os trabalhos expostos iam mudando com certa frequência. Em uma reportagem do Correio do Povo, dois meses após a abertura

65- A obra da imagem da artista Joana de Azevedo Moura não é a mesma que está no acervo do museu mas é semelhante; por isso, é possível reconhecer o seu trabalho, mas não é possível dar mais informações técnicas, como título, ano, etc. 


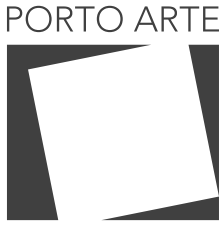

Revista de Artes Visuais

v. 25 ก. 43 Jan/jun 2020 e-ISSN: 2179-8001

da Sala de Tapeçaria, lê-se que "são duas dezenas de trabalhos das tapeceiras do Rio Grande do Sul com destaque do mestre baiano que foi Genaro de Carvalho. Ocupa essa mostra uma sala especial dessa instituição" (TAPEÇARIA, 1979, p. 18). Se compararmos com a lista inicial da sala, o artista Genaro não estava incluso nem aparece nas fotos. Também, em outra reportagem sobre a sala de tapeçaria, agora no Boletim do Margs, está escrito:

O Núcleo de Acervo do Museu de Arte do Rio Grande do Sul, [...], realizou uma reformulação geral do Salão, com destaque para os artistas gaúchos e uma nova montagem da Sala de Tapeçaria, criando ambientes nos quais destacam-se as cerâmicas do Acervo (BOLETIM, 1983, p. 10).

Essa reportagem corrobora a hipótese de que a sala recebia novas obras e mudanças em sua expografia, tendo até interferências de outros suportes artísticos, como a cerâmica, na década de $\mathbf{1 9 8 0}$. Por essa razão, é importante destacar a importância da sala de tapeçaria em uma instituição museal que, além de conservar e expor as produções têxteis, teve um papel legitimador no sistema da arte, contribuindo para uma valorização do suporte têxtil. Compreendendo a importância simbólica desse espaço, Zoravia Bettiol lamentou (e criticou), em entrevista, o fim da sala, que ocorreu em 1985, comentando que:

Como artista têxtil eu sugiro que, com o fechamento da Sala de Tapeçaria do MARGS, as obras de arte têxtil sejam expostas na Pinacoteca do Museu. E coleções que são apresentadas na sala cedida pelo MARGS ao Museu de Arte e Tradição Popular, na minha opinião, estão absolutamente deslocadas num museu de artes plásticas. Essas coleções, que são boas, deveriam ir a um outro tipo de museu e o bom espaço que elas ocupam poderia ser ocupado, futuramente, pelas tapeçarias (BOLETIM, 1985, p. 24).

Categórica em sua posição de artista têxtil e professora de tear, Zoravia Bettiol defendeu, fortemente, a sala cedida por seis anos no Margs, pois ela sabia a importância e o papel de destaque que a tapeçaria teria em possuir um espaço exclusivo, já que algo assim era raro em outros museus de arte, devido ao papel secundário que a tapeçaria tinha nas artes. Mesmo com o fechamento da sala, o museu continuaria expondo seu acervo de tapeçaria e, a partir da década de 1980, cederia espaço para o Centro Gaúcho da Tapeçaria Contemporânea, tema do próximo capítulo. 


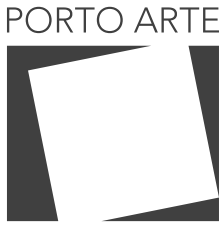

Revista de Artes Visuais

v. 25 ก. 43

Jan/jun 2020 e-ISSN: 2179-8001

\section{Décadas de 1980 a 2000: o Centro Gaúcho da Tapeçaria Contemporânea}

Nos anos 1980, ocorreu o maior número de exposições realizadas com tapeçaria entre as sete décadas pesquisadas. Isso é um reflexo da década de 1970, período em que o interesse pelo têxtil aumentou nas artes, com um grande número de artistas produzindo. Em 1976, foi criado o Centro Brasileiro da Tapeçaria Contemporânea (CBTC), cujo objetivo era "promover e incrementar a Arte da Tapeçaria [...]. Reunir, estreitar, intercambiar, expor, aumentar e entrelaçar as relações entre os artistas tapeceiros, do país e do exterior" (BOLETIM CBTC, [1976], p. 1). Com a grandiosidade do país, houve o desejo de promover centros regionais que "pudessem efetivamente congregar os artistas e artesãos tapeceiros" (SCARINCI, 1981, p. 5). Zoravia Bettiol e Liciê Hunsche eram associadas do CBTC e, sabendo da necessidade da criação de núcleos têxteis regionais e do grande número de tapeceiras existentes no sul (muito devido às aulas de Zoravia Bettiol e Yeddo Titze), essas duas artistas uniram outras tapeceiras e criaram o Centro Gaúcho da Tapeçaria Contemporânea em 1980.

Tendo sua primeira reunião no dia 21 de janeiro de 1980, com a participação de Liciê Hunsche, Heloisa Crocco, Sonia Moeller, Joana de Azevedo Moura, Aly Chaves, Helena Dorfmann, Carla Obino, Eleonora Fabre, Renata Rubim e Inge Spieker, o Centro surgiu como uma associação de interessadas pela tapeçaria e por técnicas têxteis, que foi crescendo ao passar do tempo. Basicamente, o CGTC funcionou da seguinte maneira: entrar no grupo, normalmente, era por indicação. Analisados o interesse e a produção da possível nova candidata, esta pagaria uma mensalidade que servia para pagar despesas de ações do CGTC. Havia reuniões, uma vez por mês, momento em que eram discutidas questões e em que todas as participantes eram colocadas a par das informações atuais. Esses encontros ocorriam, geralmente, nas casas ou nos ateliês de associadas, mas, principalmente, na residência da presidente, pois havia uma diretoria, composta por presidente, vice-presidente, secretária, tesoureira e conselho fiscal, que mudava de dois em dois anos (GRIPPA; BOSAK, 2018, p. 2-3).

Depois de alguns meses, mais artistas se associaram ao Centro, que chegou a ter, durante seus 20 anos de atuação, em torno de 200 associados de diversas cidades do Rio Grande do Sul e de outros estados do Brasil. Uma das atividades frequentes realizadas pelo Centro, além das reuniões mensais e trocas de materiais sobre o têxtil, foi a realização de exposições, tendo em Porto Alegre as duas instituições que mais abrigaram mostras do CGTC: o Centro de Cultura Municipal e o Museu de Arte do Rio Grande do Sul. 


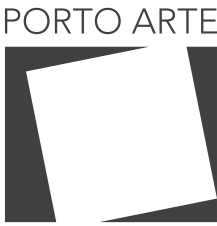

Revista de Artes Visuais

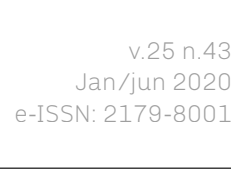

Quadro 3: Exposições e acervo MARGS das décadas de 1980 e 1990 Fonte: Elaborado pela autora, a partir de dados da pesquisa (2019)

\begin{tabular}{|c|c|c|c|}
\hline ANO & EXPOSIÇÃO DE TAPEÇARIA & TÍTULO DA EXPOSIÇÃO & $\begin{array}{c}\text { DOAÇÕES PARA O ACERVO DO } \\
\text { MARGS }\end{array}$ \\
\hline 1980 & 1 & Tapeçaria de Concessa Colaço, artista luso-brasileira & Concessa Colaço \\
\hline \multirow{4}{*}{1981} & \multirow{4}{*}{4} & O evangelho na sela, tapeçarias de Salomé Steinmetz & \\
\hline & & $\begin{array}{l}\text { 1ª Mostra de artistas gaúchos. Desenhos, tapeçarias } \\
\text { e esculturas, realizado na Câmara dos Deputados/ } \\
\text { Brasília }\end{array}$ & \\
\hline & & Mostra de tapeçarias das alunas de Carla Obino & \\
\hline & & Tapeceiros Liciê Hunsche e Jacques Douchez & \\
\hline 1982 & 1 & $\begin{array}{c}\text { Mostra: objetos rendados, tapeçarias de Vera Beatriz } \\
\text { Stédile Záttera }\end{array}$ & $\begin{array}{l}\text { Jacques Douchez } \\
\text { Liciê Hunsche ( } 2 \text { obras) } \\
\text { Vera Stédile Záttera }\end{array}$ \\
\hline 1983 & 0 & & \\
\hline \multirow{2}{*}{1984} & \multirow{2}{*}{2} & O mundo transfigurado de Zorávia Bettiol & \multirow{2}{*}{ Zoravia Bettiol } \\
\hline & & Batik & \\
\hline \multirow{3}{*}{1985} & \multirow{3}{*}{3} & Annete Kaplan, tapeçarias & \multirow{3}{*}{ Norberto Nicola } \\
\hline & & A arte de Zoravia Bettiol, $1955-1985$ & \\
\hline & & Exposição Nacional de Arte Têxtil 85 & \\
\hline 1986 & 0 & & \\
\hline 1987 & 1 & $\begin{array}{l}\text { Tramas e tensões. } \\
\text { Ana Norogrando }\end{array}$ & \\
\hline \multirow[b]{2}{*}{1988} & \multirow[b]{2}{*}{2} & Fiber art - Parternship internacional & \\
\hline & & Primeiro encontro latino-americano de minitêxteis & \\
\hline \multirow{3}{*}{1989} & \multirow{3}{*}{3} & Evento Têxtil $₫ 89$ & \multirow{3}{*}{ Ana Norogrando } \\
\hline & & $\begin{array}{l}\text { Tapeçaria, joias e quimonos, artista italiana Orieta } \\
\text { del Sole }\end{array}$ & \\
\hline & & Acervo Margs: tapeçaria & \\
\hline 1990 & 1 & 10 anos do CGTC & $\begin{array}{c}\text { Erica Turk } \\
\text { Maria Helena Bervian }\end{array}$ \\
\hline 1991 & 1 & Segundo Encuentro Latino Americano de Mini Textiles & \\
\hline 1992 & 0 & & \\
\hline \multirow{3}{*}{1993} & \multirow{3}{*}{1} & Acervo Margs: tapeçarias e desenhos & \\
\hline & & Trama (tapeçarias da prefeitura) & \\
\hline & & Fórum Têxtil & \\
\hline \multicolumn{4}{|l|}{1994} \\
\hline \multicolumn{4}{|l|}{1995} \\
\hline 1996 & 1 & Uma visão sobre a arte têxtil brasileira & \\
\hline
\end{tabular}

Na década de 1980, das 17 exposições têxteis que ocorreram no Margs, quatro foram organizadas pelo CGTC: "Exposição Nacional de Arte Têxtil 85", "Fiber art " Parternship Internacional", "Primeiro Encontro Latino-Americano de Mini Têxteis" e "Evento Têxtil - 89". E das nove exposições individuais, cinco foram de associadas do Centro: Ana Norogrando, Carla Obino, Liciê Hunsche, Vera Beatriz Stedille Zattera ${ }^{67}$ e Zoravia Bettiol. Na década de 1990, das seis exposições sobre o tema, quatro foram realizadas 


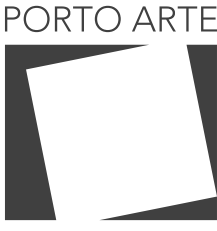

Revista de Artes Visuais

$\vee 25 n .43$

Jan/jun 2020 e-ISSN: 2179-8001

pelo CGTC: "10 anos do CGTC", "Segundo Encontro Latino-Americano de Mini Têxteis", "Fórum Têxtil" e "Uma Visão sobre Arte Têxtil Brasileira".

Para um suporte que tivera um espaço secundário nas artes até então, nas décadas de 1970 e 1980 a tapeçaria adquiriu um reconhecimento no sistema, tendo o CGTC, na cidade de Porto Alegre e no Estado, um papel importante na legitimação do suporte, organizando eventos e exposições abertas ao público. E nessas atividades o Margs foi um parceiro do Centro, pois, além de abrigar diversas exposições coletivas e individuais, também constituiu sua coleção de trabalhos. Mas mesmo assim, após esse período de grande difusão, a técnica e a coleção do Margs foram esquecidas pela historiografia.

Esse esquecimento é em parte consequência da própria década de 1990, que já começou a mostrar um desinteresse pelo suporte têxtil, diminuindo a quantidade de mostras coletivas e, praticamente, eliminando as individuais. Quando estudei sobre o CGTC, muitas associadas citaram que nos anos de 1990 o Centro começou a perder força, levando ao encerramento das suas atividades no ano 2000 (GRIPPA; BOSAK, 2018). Algumas das razões levantadas foram que algumas artistas começaram a desenvolver sua produção em outro suporte e não havia mais pessoas interessadas no tecer, inexistindo uma nova geração para seguir o movimento, que se iniciou na década de 1970 (GRIPPA; BOSAK, 2018). Somente em 2004 ocorreria uma exposição dedicada ao tema, "A arte da tapeçaria, da Coleção Petit Palais" (Paris/França). A mostra exibiu peças dos séculos XVII e XVIII, vindas do museu francês, apresentando tapeçarias mais clássicas, com exemplares de Gobelins (A ARTE, 2004).

Após essa exposição, por algum tempo não houve mais mostras explorando o tema, e a tapeçaria foi sendo esquecida como um suporte da arte, com suas próprias características e peculiaridades; e a autonomia que ganhou no século XX foi sendo apagada. Muitas tapeçarias ficaram enroladas na reserva técnica do Margs, sem terem uma exposição dedicada à sua história, mas tendo visibilidade em algumas mostras, no período de direção de Gaudêncio Fidelis (2011/2014).

Nesse período, as tapeçarias do acervo do Margs foram expostas em mostras coletivas, sob temas diversos, mas duas chamam a atenção pela quantidade de tapeçarias expostas e pelos temas das mostras. A primeira aconteceu em 2011, intitulada "O Museu Sensível", que teve como objetivo mostrar os trabalhos de artistas mulheres do acervo. Nessa exposição, 17 tapeçarias foram expostas. A segunda, "Geografia da criação - Arte, Design e Moda", de 2014, quis mostrar a relação entre essas três áreas, em levando em consideração à criação, independentemente de seus produtos finais e finalidades.

Ambas as mostras expuseram algumas das tapeçarias do acervo, o que é significativo, pois reapresentaram para o grande público a arte têxtil que fez parte da história da arte sulina e do próprio Margs. Porém, observamos que a razão para essas tapeçarias estarem expostas estava antes ligada aos temas generalistas, a saber: uma técnica vinculada ao "saber feminino", na qual as mulheres se destacam por terem um conhecimento maior de técnicas ligados ao lar, como o tear e o bordado; e a segunda exposição, que tinha como objetivo apresentar, sem desigualdades, as áreas de arte, design e moda. Uma tentativa válida, mas que deixou a tapeçaria em uma situação 


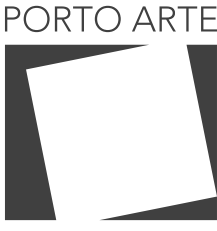

Revista de Artes Visuais

$\vee 25 n .43$

Jan/jun 2020 e-ISSN: 2179-8001

ambígua, entre o design e a arte, obscurecendo a própria autonomia do suporte, que foi uma das buscas dos artistas envolvidos na produção do têxtil no século XX.

Se nos dois exemplos as tapeçarias foram conectadas a conceitos que usualmente são ligados ao suporte, que muitas vezes dificultam a sua inserção no sistema das artes, as mostras desconsideraram a autonomia conquistada ao longo do século XX, para a qual tantos artistas lutaram. Considerando que toda instituição museal tem como um dos objetivos expor seu acervo ao grande público, para que esse possa conhecê-lo e apreciá-lo é, entretanto, importante entender a trajetória dessas peças e as peculiaridades de cada suporte, para melhor compreender a própria obra e a sua ligação histórica com o museu que a conserva. Parece-nos que falta, na atualidade, um interesse do Margs em atualizar essa história, na qual a própria instituição teve importante protagonismo com as várias exposições que abrigou e com a formação do seu expressivo acervo.

Recontar a trajetória dessas peças não é apenas valorizar os trabalhos artísticos, mas é perceber a própria instituição como legitimadora desse suporte, que foi esquecido e marginalizado dentro da história da arte.

\section{REFERÊNCIAS}

A ARTE da Tapeçaria - Coleção do Petit Palais, Paris. São Paulo: Pinacoteca do Estado, 2004.

ALMEIDA, Lucia Machado de. GENARO - Exposição Museu de Arte de Porto Alegre e Belo Horizonte. Belo Horizonte, 1958.

ARTISTAS da Tapeçaria Moderna. São Paulo: Passado Composto XX, 2012.

BOLETIM CBTC. São Paulo: Centro Brasileiro da Tapeçaria Contemporânea, n. 1, [1976] BOLETIM informativo. Porto Alegre: Margs, n. 11, nov, 1983.

CARVALHO, Ana Albani. Complexa Trama: Arte têxtil por Zoravia Bettiol, 2007. In: BETTIOL, Zoravia. Zoravia Bettiol: a mais simples complexidade. Porto Alegre: Território das Artes, 2007.

CÁURIO, Rita. Artêxtil no Brasil: Viagem pelo mundo da tapeçaria. Rio de Janeiro: [S.n.], 1985.

COTTON, Giselle Eberhard; JUNET, Magali. From tapestry to Fiber Art: The Lausanne Biennials 1962 - 1995. Milão: Skira Editore, 2017.

FOLETTO, Vani Terezinha; BISOGNIN, Edir Lucia. As Artes Visuais em Santa Maria: contextos e artistas. Santa Maria: Pallotti, 2001.

FUNDAÇÃO ARMANDO ALVARES PENTEADO. Tapeçaria I Mostra. São Paulo, 1974.

GONZAGA, Luiz. Luiz Gonzaga: entrevista [17 fev. 2018]. Entrevistadora: Carolina Bouvie Grippa. Porto Alegre, 2018.

GRADIN, Maria Izabel de Souza. As trienais de tapeçaria do MAM SP de 1976 A 1982.

In: ENCONTRO DE PÓS-GRADUANDOS DO INSTITUTO DE ESTUDOS BRASILEIROS,

1. Culturas e identidades brasileiras. São Paulo: Instituto de Estudos Brasileiros, 2016. Disponível em: http://www.livrosabertos.sibi.usp.br/portaldelivrosUSP/catalog/book/80. Acesso em: 11 nov. 2018. 


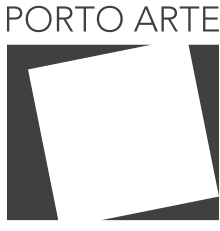

Revista de Artes Visuais

$\vee 25 n .43$ Jan/jun 2020 e-ISSN: 2179-8001

GRIPPA, Carolina Bouvie; BOSAK, Joana. A urdidura da trama: o Centro Gaúcho da Tapeçaria Contemporânea. In: SEMINÁRIO DE HISTÓRIA DA ARTE, 17. Anacronias do tempo, Pelotas, Centro de Artes, UFPEL, n. 7, 2018. Disponível em: https://periodicos.ufpel.edu.br/ojs2/index.php/Arte/article/view/13487. Acesso em: 2 jan. 2019.

MAGRISSO, Ronete. [Carta] 2 maio 1984 [para] Evelyn Berg Ioschpe. 1p.

MATTAR, Denise (org.). Norberto Nicola - Trama Ativa. São Paulo: Imprensa Oficial do Estado de São Paulo: Pinacoteca do Estado de São Paulo, 2013.

MARGS. Ficha Técnica. Porto Alegre: Margs, [s. d.]. 1f. Datilografado.

MARGS. Tapeçarias: Genaro de Carvalho (artista baiano). Porto Alegre: Margs, 1959. 1f. Datilografada.

MARGS. Semana do Margs - inauguração Sala de Tapeçaria. Porto Alegre: Margs, 1979. 1f. Datilografado.

MATTAR, Denise (org.). Norberto Nicola - Trama Ativa. São Paulo: Imprensa Oficial do Estado de São Paulo, Pinacoteca do Estado de São Paulo, 2013.

MOELLER, Sonia. [Carta] 8 set. 1979, Porto Alegre [para] diretor Margs, Porto Alegre. 1p.

RAMOS, Paula; GOMES, Paulo. Zoravia Bettiol, o lírico e o onírico. Porto Alegre: Imagens da Terra, 2017.

SAFRA. Museu de Arte do Rio Grande do Sul. São Paulo: Editora Safra, 2001.

SCARINCI, Carlos. Apresentação. In: $1^{a}$ MOSTRA do Centro Gaúcho da Tapeçaria Contemporânea. Porto Alegre, 1981.

SIMIONI, Ana Paula. Cavalcanti. Regina Gomide Graz: modernismo, arte têxtil e relações de gênero no Brasil. Revista do IEB, São Paulo, n. 45, p. 87-106, set. 2007. Disponível em: http://www.revistas.usp.br/rieb/article/view/34583. Acesso em: 17 jun. 2017.

TAPEÇARIA do Margs. Correio do Povo, Porto Alegre, p. 18, 4 dez. 1979.

TITZE, Yeddo. Um museu com infinitas possibilidades, 2005. In: GOMES, Paulo; GROCCO, Vera Regina (org.). Memória do Museu. Porto Alegre, 2005.

ARTISTAS da Tapeçaria Moderna. São Paulo: Passado Composto XX, 2012.

UFMG. Tapeçaria Brasileira. Belo Horizonte, 1974.

ZIELINSKY, Mônica. Evento Têxtil/85: um espaço para reflexão, 1985. Boletim Informativo MARGS, Porto Alegre, n. 25, p. 11-14, jul./ago./set. 1985. 


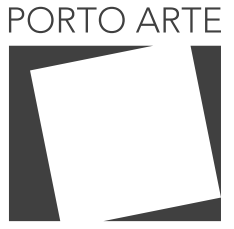

Revista de Artes Visuais

v. $25 \mathrm{n} .43$

\section{Paulo César Ribeiro Gomes}

Doutor em Artes Visuais - Poéticas Visuais pela Universidade Federal do Rio Grande do Sul (2003). Professor Associado no Departamento de Artes Visuais e no Programa de Pós-Graduação em Artes Visuais do Instituto de Artes da UFRGS.

\section{Carolina Bouvie Grippa}

Bacharel em Moda pela Universidade Feevale, atualmente está cursando Bacharelado em História da Arte na Universidade Federal do Rio Grande do Sul e é bolsista de iniciação científica na pesquisa História da Arte e Cultura de Moda, coordenado pela Prof. Dra. Joana Bosak. 